\title{
EX SAIF SEREEA II - The Field Hospital Clinical Report
}

\author{
MCM Bricknell, LA Wright
}

\begin{abstract}
This paper places on record the clinical activity of the hospital facilities run by 22 Field Hospital on Exercise SAIF SEREEA II in Oman from August to November 2001. There were 1322 episodes of illness resulting in a hospital admission. The mean rate of admission was 1.96 patients per thousand per day (SD 13.62). The main causes of admission were gastrointestinal illness, conditions related to the heat and injuries. The reporting of health service utilisation data is an important duty of medical personnel during overseas deployments in order to add to the dataset available for the estimation of medical workload for future operations.
\end{abstract}

\section{Introduction}

Ex SAIF SEREEA II (Ex SS II) was a Combined and Joint exercise involving UK and Sultanate of Oman Forces held in OMAN between August and November 2001. 22 Field Hospital was tasked with the provision of all levels of hospital support for Ex SSII. This divided into 3 separate hospital sites: a 100 bed hospital at Thumrait from 21 Aug to 5 Nov 01, a 10 bed hospital at the Convoy Support Centre from $23 \mathrm{Sep}-7 \mathrm{Nov}$ 01 and a 100 bed hospital at the Forward Support Group (FSG) from 3 Oct to $7 \mathrm{Nov}$ 01 . A previous paper has reported the clinical activity in the hospital facility based in Thumrait for both Ex SAIF SERREA and subsequent military operations in Afghanistan (1). This paper compliments the previous report by providing the complete field hospital data set for Ex SAIF SERREA.

Kingdom Support

Command (Germany)

British Forces Post

Office 140

Email:

starlight18@bfgnet.de

*formerly Commanding Officer of 22 Field Hospital for Ex SAIF SEREEA.

Lt Col LA Wright QARANC

SO1 Nursing

Headquarters Medical Group

Imphal Barracks, Fulford Road, York YO10 4HD

\section{Methodology}

Information on all patients in the Thumrait and FSG hospitals was copied from the Admission and Discharge books and entered onto a database managed by the Patient Tracking Officers under the supervision of the SO1 Clinical Governance (LW). The basic demographic details, diagnosis, and admission and discharge dates were
Table 1. Summary of clinical activity for each field hospital. extracted from the hospital record on discharge. The diagnosis was coded using the J97 system (2). Some patients were transferred between hospitals and so were entered on both databases. Both datasets were merged at the end of the exercise and the duration of hospital admission for these 'double entries' was combined. Individuals who were admitted for separate episodes of illness were counted twice. The size of the hospital at the CSC precluded the appointment of a patient tracking officer, thus the information for the small number of patients admitted is not included in the analyses reported in this paper. Some patients may have been 'bedded down' for minor conditions in primary care centres at extremes of the exercise area (the RAF medical centre in Muscat, the Commando Medical Squadron supporting 3 Commando Brigade and RN ships) and will not have been included in this dataset.

\section{Results}

Table 1 shows a summary of clinical activity for each field hospital. After aggregating transfers between facilities as described in the methods section, a total of 1332 episodes of illness resulted in hospital admission.

The number of new admissions (excluding intra-hospital transfers) was extracted from the dataset. All units provided daily personnel numbers (PERSREP signals). This was used to obtain numbers of military personnel (population at risk, PAR) on Ex SSII on a daily basis in order to calculate a daily rate of hospital admission for the force.

Figure 1 shows the daily rates of hospital admission for all personnel on Ex SAIF SEREEA. The mean rate of admission was 1.96 patients per thousand per day (SD 13.62). Figure 2 shows the breakdown of all hospital admissions by J97 data code.

Patients were either returned to unit or evacuated back to UK by air ('aeromedded'). Patients were aeromedded on the authority of a consultant or the senior medical officer (senior GP) at the Rear Hospital. Personnel with pre-existing medical conditions or who

\begin{tabular}{|l|l|l|l|}
\hline Group & Thumrait & CSC & FSG \\
\hline Dates & 21 Aug - 5 Nov 01 & 14 Sep - 12 Nov & 01 Oct - 2 Nov \\
\hline Primary Health Care & 2506 & 554 & 1153 \\
\hline Admissions & 1086 & 74 & 322 \\
\hline
\end{tabular}




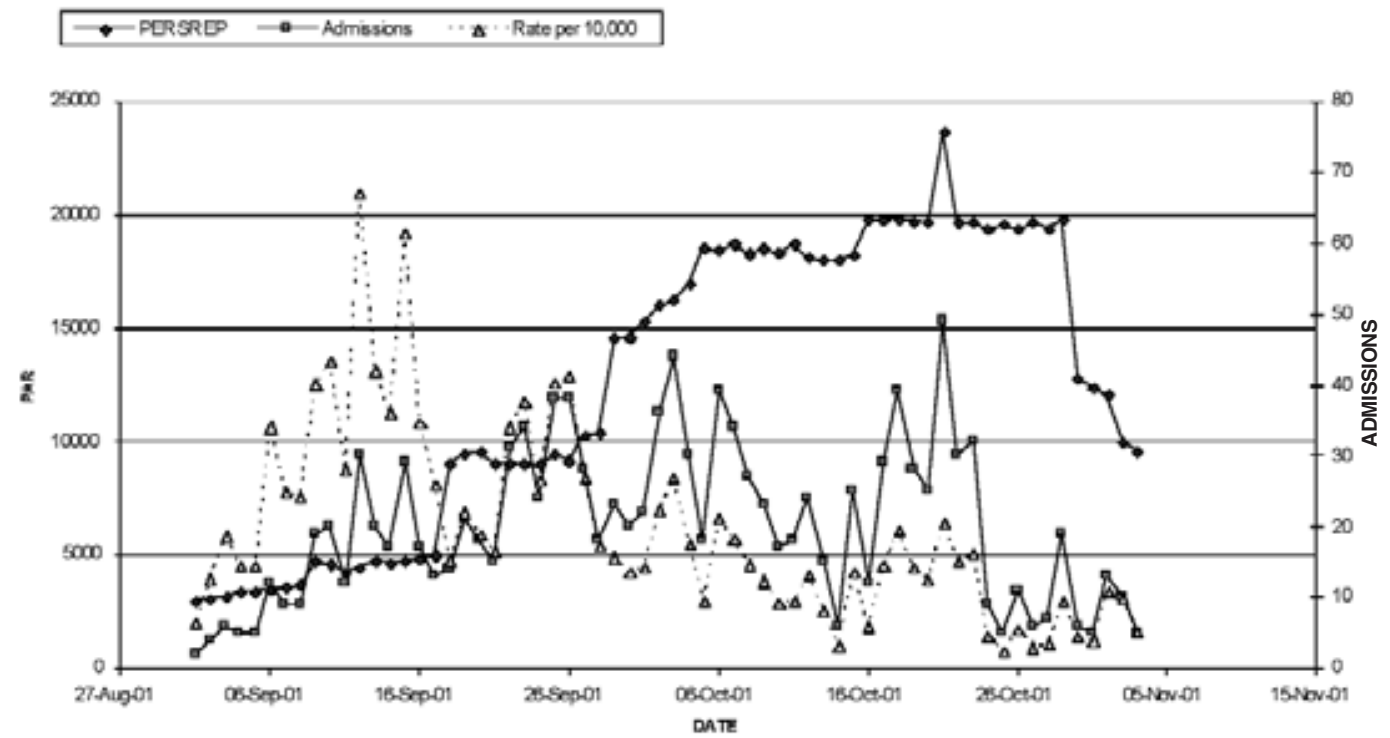

Fig 1. Daily Rates of Hospital Admission for Ex SAIF SEREEA.

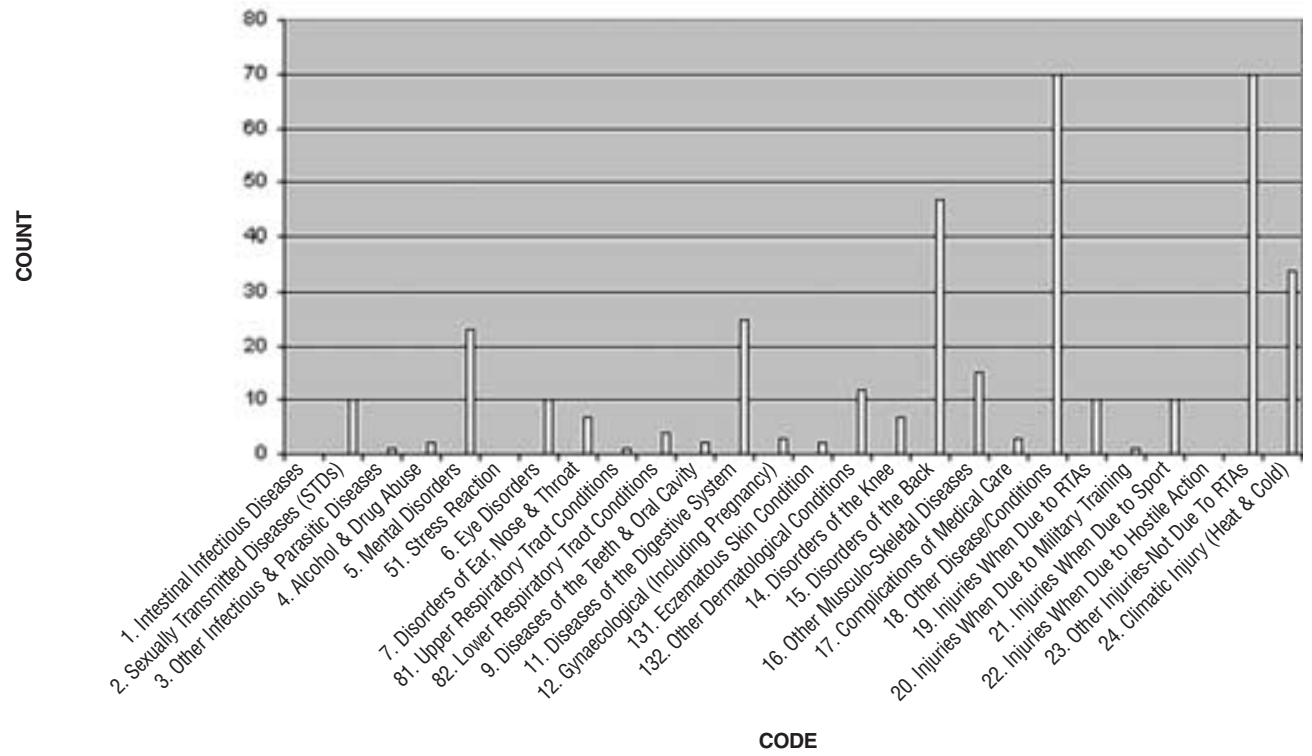

Fig 2. Hospital Admission by 997 Code.

clearly required investigation or treatment beyond the capability of the field hospitals were aeromedded. There was no formal 'holding' policy because the exercise was so intense, and of such limited duration, that there was little to be gained from retaining personnel who were unlikely to recover in a short time. Figure 3 shows the length of stay for personnel admitted to the field hospitals. This includes personnel who were returned to unit and also those who were 'aeromedded'.

A total of 369 personnel were 'aeromedded' from the Rear field hospital to UK. This is $27.7 \%$ of hospital admissions. The breakdown of this group by J97 code is shown at Figure 4.

\section{Discussion}

Figure 1 shows that the admission rate for the exercise was highly variable. The high incidence in the first half of September was the result of admissions for heat related conditions. There are three periods of large numbers of admissions: 23-27 Sep, 2-6 Oct and 18-23 Oct. Gastro-enteritis was the main cause of admission during these periods. The PERSREPS for naval forces were added to the denominator on 29 Sep 01. These individuals were accommodated and employed afloat in an air-conditioned environment and so were not exposed to the same conditions as those working ashore. It is possible that a significant element of the reduction in admission rate after this date reflects this increase in the PAR who were at substantially lower risk of ill-health.

The medical plan estimated a hospital admission rate of $1.65 / 1000$ per day. The mean admission rate was $1.96 / 1000$. However, Figure 1 shows considerable variation in this figure, which emphasises that a reserve capacity is required to ensure that demand can be met.

The distribution of diagnosis for admission is shown in Figure 2. Diseases of the digestive system were the main cause of admission. In spite of an aggressive 


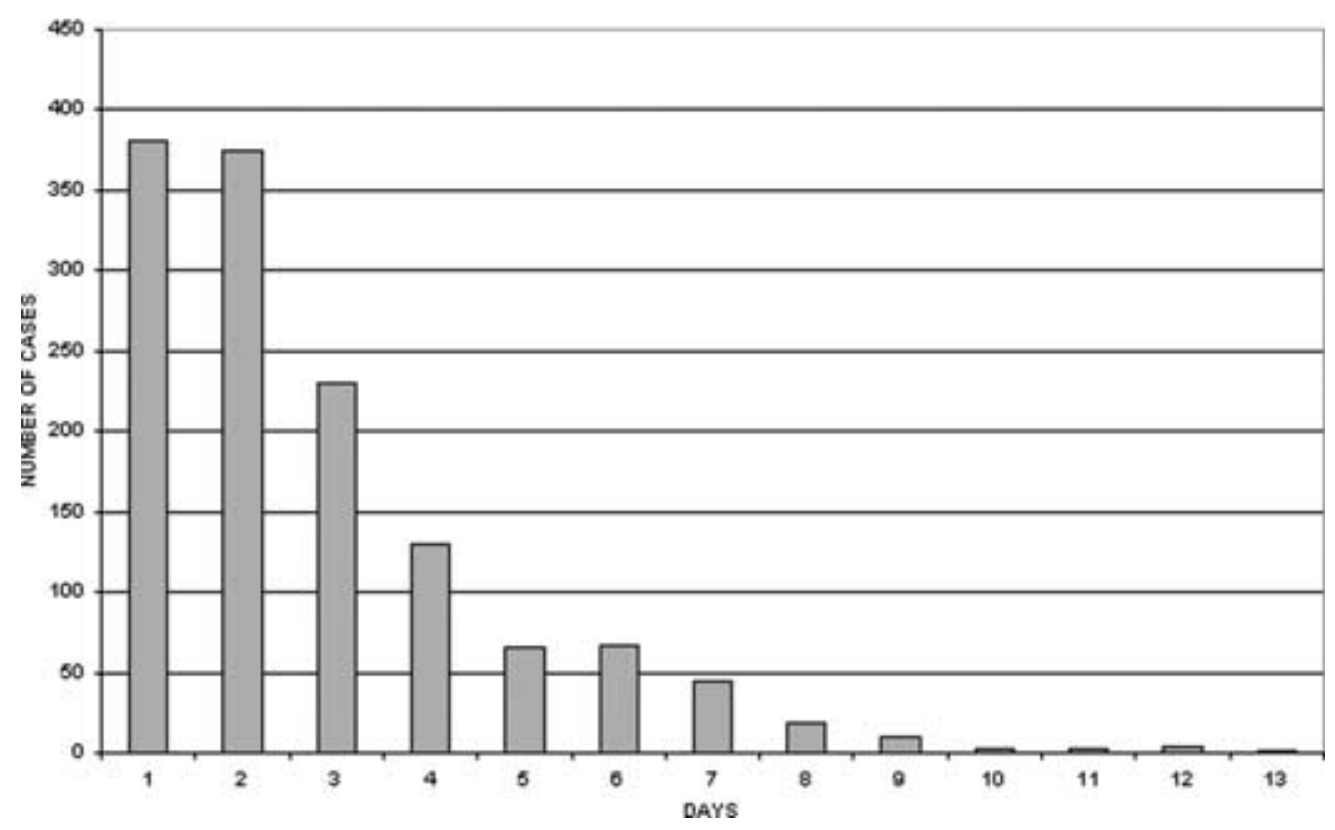

Fig 3. Duration of stay of hospital admissions.

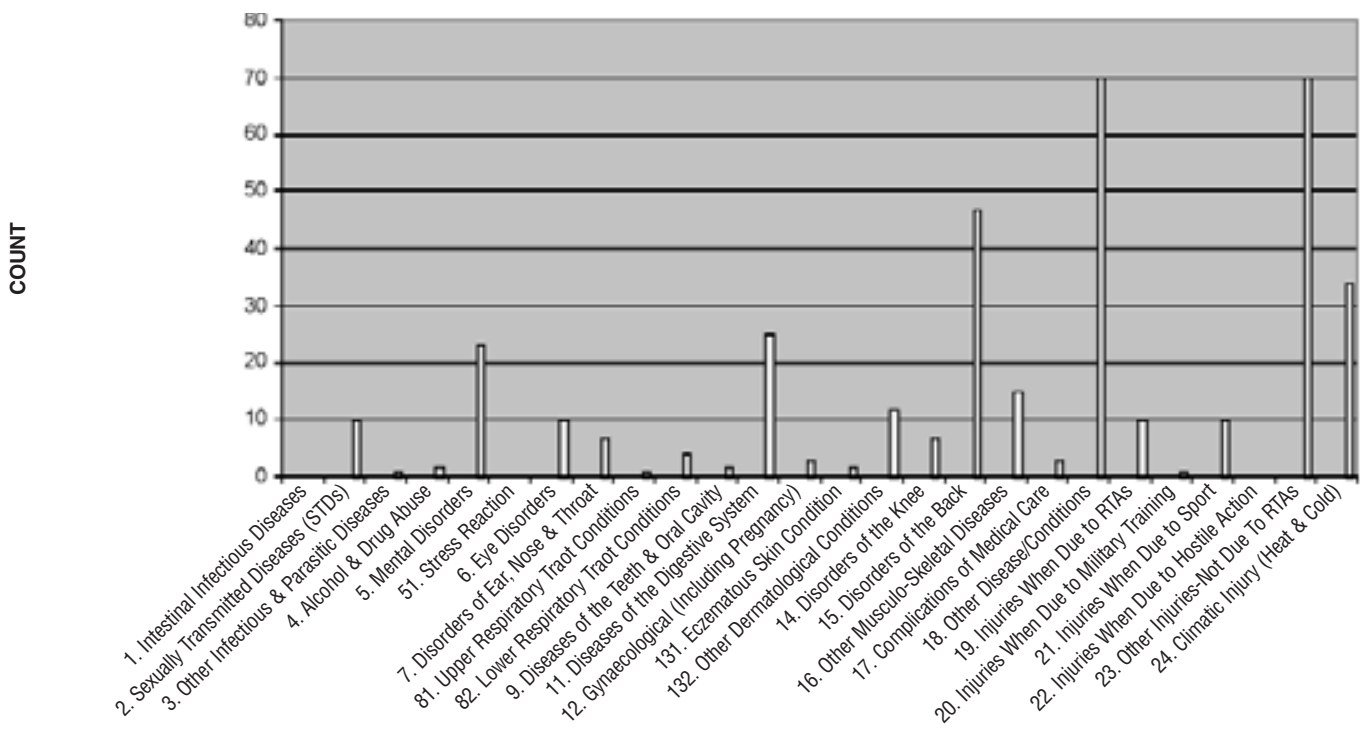

Fig. 4. Personnel Aeromedded by 797 Code.

CODE

environmental health protection plan, there were a number of outbreaks of a 'diarrhoea and vomiting' symptom complex. These were fully investigated by military environmental health personnel but no infective organism was identified. Heat related conditions were the second greatest cause of hospital admission. There were no cases of heatstroke. There was some difficulty codifying these cases as a large number of patients with raised core temperatures were suffering from intercurrent illnesses and were not cases of heat exhaustion. A small number of patients were admitted as a result of hyponatraemia, including one who required emergency transfer to a regional intensive care unit. This led to a local review of the guidelines for water intake for the prevention of heat illness and all personnel were recommended to increase their salt intake at meal times.
Aggregated together (codes 19, 21 and 23), injuries were the next major cause of admission. This is a predicted consequence of military training and reflects the previous report from Bosnia (4). There were fewer injuries due to sport in this series, reflecting the intense nature of the exercise and the few sporting opportunities available.

Figure 3 shows the distribution of length of stay for the hospitals. The majority of personnel were admitted for short, selflimiting conditions or were aeromedded within a short period of their admission. The quick recovery of many patients also necessitated a simple process for returning patients to their parent units. Occasionally this proved to be a challenge as some units had moved to a different location in the exercise area after the patient had been admitted. The Logistic Brigade established a 
temporary holding unit in each major exercise area to which patients were discharged. This freed up hospital beds and exercised the process for the replacement of battle casualties that would be needed on operations. This data shows how the interrelationship between admission rates, rates of aeromed and rates of discharge link to bed occupancy. It is important for a medical plan to include reserve capacity.

At the peak of the exercise, aeromed flights were occurring every 2-3 days and so aeromedical evacuation of patients could be achieved within a very short period of the decision being made. Pre-existing conditions are a well recognised cause of aeromed from operational theatres $(3,4)$. Subjectively, this was also found on Ex SAIF SEREEA. This was particularly the case for those with back conditions, who were not able to cope with the physical demands of living in field conditions. It was also impractical to retain those individuals who required the support of a community psychiatric nurse. The majority of those aeromedded for climatic injury had had a second episode during the exercise and so were removed from the environment in accordance with existing medical policy.

\section{Conclusion}

This paper is the result of data collected using the hospital patient registration system. The data demonstrates the importance of disease and non-battle injury as a source of clinical work for the military medical services and provides a baseline for operations in desert environment. It was possible to calculate admission rates because the population at risk was the whole exercise population and there was a system for recording this figure. It is suggested that deployed medical units should consider publishing their activity in the Journal in order to provide a cumulative record that can be used to improve our collective capability to predict the utilisation of medical services in the field.

\section{References}

1. GW Becker and TJ Laundy. A lesson not yet learned. F R Army Med Corps.2003;143:274-276.

2. J97 as a tool to investigate the effects of the Southeast Asia Smog. I Roy Army Med Corps 1999;145:120-124.

3. Hodgetts TJ and Ratcliffe GE. Gulf Medical AuditAn Analysis of Medical Casualties Evacuated to the UK from the Gulf During Operation Granby. $\mathcal{F} R$ Army Med Corps 1992;138:9-13.

4. Adams MS. Pre-existing disease In British Army Patients Aeromedically Evacuated from The former republic of Yugoslavia. If $R$ Army Med Corps 1996;142:97-100. 